\title{
Can coercion be justified when it benefits the poor? The case of commercial surrogacy industry in India
}

\author{
Packiaraj Asirvatham \\ An independent researcher, India. \\ Email: Packiaraj.a@gmail.com
}

\begin{abstract}
Commercial surrogacy in India is a booming industry however the raising number of poor illiterate women's participation as commercial surrogate poses serious question of coercion, on the other hand it economically empowers them. In this context, this article analyses the crucial question, can coercion be justified when it benefits the poor by investigating commercial surrogates' life stories and looking into the various types of coercion discreetly operates. It concludes with few recommendations which can help in empowering poor commercial surrogates who involved in commercial surrogacy industry in India.
\end{abstract}

\section{Key Word: Commercial surrogacy, coercion, poverty, reproductive tourism, India}

Introduction: Commercial Surrogacy in India is a crucial bio ethical issue. According to an Indian law commission report commercial surrogacy has been viewed as a golden pot for poor surrogate women on the one hand, and on the other hand as a great help for childless couples ${ }^{1}$. It is estimated that nearly 200,000 clinics across the India offer artificial insemination, IVF, and surrogacy. The Confederation of Indian Industry analyzed that commercial surrogacy had grown to a $\$ 2.3$ billion industry in India in $2012^{2}$. In this context, emerging ethical issues of commercial surrogacy are of serious concern as the commercialization of reproduction can lead to exploitation of women, unfair distribution of economic benefits, and legal battles especially in cross-border commercial surrogacy ${ }^{3,4}$. Presently, little research exists about how uneducated, rural women who participate in commercial surrogacy grasp the facts of advanced medical treatments. Moreover, how do they correspond with commissioning parents from abroad? Do they really understand the surrogacy contracts? Are they voluntarily involved in the process or coerced? In this context, an increasing number of surrogate mothers from economically deprived backgrounds pose serious questions about coercion.
Approach: This paper explores the basis of a commercial surrogate's coercion and portrays how they are forced to participate in commercial surrogacy by their family, private sector clinics, and the governments. Then it focuses on the ethical question: can this coercion be justified since it helps their economic development? This study will be approached in four stages 1. a survey the presence of coercion in the scholarly journals 2. an exploration of the main forces of coercion 3. an ethical analysis of the ethical acceptability of coercion in the context of economic development of poor communities and 4. a series of suggestions to eliminate coercion in the commercial surrogacy industry.

Limitation: The parties involved in crossborder commercial surrogacy are the commissioning parents, medical doctor, brokers, commercial surrogate, and family and friends of the surrogate mother; however, this study only focuses on the commercial surrogate women. Commercial surrogacy is a broad research topic where this study only focuses on cross-border commercial surrogacy. The word "coercion" used in its basic meaning of "compulsion" or "force".

The context: Cross-border commercial surrogacy is very unique. It is like an export and import business. It occurs not only between 
two parties but between citizens of two countries. The issue of cross-border commercial surrogacy in India is a very modern phenomenon. When India opened its markets in 1991 as part of economic liberalisation many industries thrived. For instance, in the state of Gujarat, which is the most industrially developed state, they adopted commercial surrogacy as one of their main business, so it has become one of the largest industries. It is claimed that the district of Anand, Gujarat is the unofficial capital of the commercial surrogacy industry ${ }^{5}$.

As a starting point to understand the issue of coercion from practical contexts, I would like to present a few of testimonies of commercial surrogates from the Anand district, the state of Gujarat, India. These testimonies are from established studies of Pande and Sarvanan who spent considerable time on the field and published their results in scholarly journals from 2009-2010. Pande has predominantly focused her studies on Hope maternity clinic in Anand where Saravanan researched in Akanshka clinic in Anand and Bavishi clinic in Ahemedbad. However, they both undertook their studies in Anand which is the core of commercial surrogacy in India.

Commercial surrogates voices: Let us move to the commercial surrogate mothers testimonies, they all express their idea on commercial surrogacy, their motivations and reason to take part in it. Salma expresses that commercial surrogacy is a majboori because of family circumstances which means compulsion or force, Anjali expressess that she is in desperate need for money to take care of her child, Vidyaben notes that she was convinced by her inlaws and persuaded by a nurse, Meena was convinced by her husband to become surrogate, Sapna is helping her inlaws to build a house, and Raveena committed to commercial surrogacy to save the life of her younger child ${ }^{6}$.Regina, a forty-two-year-old surrogate, was persuaded by a nurse when she met this nurse at a hospital where she treated her daughter ${ }^{7}$. In all these cases, these women are persuaded by someone and submitted themselves to the commercial surrogacy industry. This raises the question of coercion. However, Jyotsna Agnihotri Gupta argues that the impact of ART on women shifted them from subject to object and as the controller of their own body. On the contrary, in my perspective the rural women involved in the commercial surrogacy industry would have not even had the right to choose their own life partner for their marriage. If that is the case, then how can we assume that these women are the controller of their own bodies with regard to commercial surrogacy?

Types of coercion: Commercial surrogacy in India is still an unregulated industry which is operating on the basis of the guidelines from the Indian Council for Medical Research (ICMR). So every maternity clinic operates in their own way to choose commercial surrogates. Recruiting the commercial surrogates is the first and foremost step. It is very evident that formal and informal brokers are the surrogacy recruiters. They include: former surrogates, women who could not become surrogates for medical reasons, and midwifes in various hospitals. Finding and selecting a surrogate is a crucial issue since the demand is very high; for example, Dr. Khanderia, head of the clinic explains that "at the moment (in 2008 and 2009) there are more than 300 intended parents on the waiting list"6. So commercial surrogates are recruited aggressively to meet this heavy demand. Especially, there are three main ways in which these women are forced to undertake commercial surrogacy as their survival strategy: firstly, circumstances from family and husband, and the patriarchal society and its force; secondly, the economic circumstances in which the need for money forces the surrogates to undertake surrogacy, and thirdly, profit centered policies of governments which view commercial surrogacy as a beneficial industry force the women to undertake commercial surrogacy. These are three main categories in which coercion is systematically executed. 
Family driven coercion: India is still a patriarchal country where women have limited choices especially with reproduction. Predominantly the power is vested with men. Pande argues that though many women accept the fact of social stigma, they involve in this industry secretly because of the compulsion of their family ${ }^{8}$. Obviously, many of the men from poor background view their wives as a money making machine and look forward to make use of this new fortune. Private clinics also capitalize on this idea. For example, the consent of the husband is crucial in becoming a commercial surrogate. Every commercial surrogate is obliged to get consent from her husband ${ }^{8}$. Technically, to a large extent, the husband's desire to make money through his wife is easily executed by the brokers. More interestingly, there is no space for the surrogate's informed consent and the surrogacy contract is in English, a language most of the surrogates are unfamiliar with. So systematically the in-laws and the husband force the women to be a surrogate. More interestingly, most of the surrogates sideline the aspect of choice in their involvement. They attribute that it is because of their family, children, or husband and they also express that, "It was not in my hand"9. On the whole, commercial surrogates are the product of patriarchal societies who lack choices and are powerless to make decisions on their own.

\section{Economic needs based coercion: Coercion} predominantly takes place in the context of severe economic need. It is a systematic approach to target the people in need of money and coerce them to be a surrogate. Nirmala narrates how she came to be a broker by saying, "I came here to donate eggs, but I was refused because of my age. So I started getting women from my hospital. It is easy for me to find the right women because I used to be a midwife. I know which women have very young children, which ones are in desperate need of money"7. Bailey recalls a surrogate who accepted $\$ 1,500$ instead of $\$ 2,000$ when another woman offered for $\$ 1,500{ }^{10}$. Sandel claims "coercion is when people buy and sell things under conditions of severe inequality or dire economic necessity. According to this objection, market exchanges are not necessarily as voluntary as market enthusiasts suggest. A peasant may agree to sell his kidney or cornea in order to feed his starving family, but his agreement is not truly voluntary. $\mathrm{He}$ is coerced, in effect, by the necessities of his situation"11. As per Sandels definition it is very clear that commercial surrogates in India are coerced deliberately. Obviously, commercial surrogacy travels in the line of organ trafficking where brokers convince and collect the organ from the vulnerable people for payment. Ultimately this systematic coercion puts these surrogates into work. Further, Pande remarks that the sole strategy is identifying and persuading women in desperate need of money for their children and she claims that half of her interviewees are recruited by brokers ${ }^{12}$. These coerced women who are in severe economic need are further persuaded by individual counseling session. Their counseling session is all about moral justification of commercial surrogacy by differentiating it from sex work. In addition, they describe this idea through convincing parables. For example, by saying "just like renting a house for nine months", "God's gift to serve childless couple", "motherworker" and "act like a vessel" hand, a commercial surrogate may earn around $\$ 5000$ to give birth to a child which is considerably a good earning compare to her normal income per year and it is likely her 2-3 years income altogether. So it is considered as economic empowerment however taking into consideration of 10 months of intensive labor and pre term and post term physical and psychological complications and associated risks in addition to social stigma victimize the commercial surrogate. In this context, being a commercial surrogate is like bonded labor with legal contracts!

Policy driven coercion: Another very important type of coercion is from the government. Many scholars like Qadeer, Unnithan, and Jaiswal argue that commercial surrogates are systematically coerced by government policies. 
They describe how these policies target vulnerable communities. For example, Indian government classifies commercial surrogacy under medical tourism, which is one of the potential income generating methods to the country, and it encourages the inflow by giving special medical visas to foreigners ${ }^{13,14,15}$. Unnithan refers to this as "hyper-fertile bodies of poor women subject to state-backed technological intervention"16. Qadeer argues that the government is willingly commercializing public resources to favor international and private actors; consequently, it contributes to the economic growth of the country ${ }^{17}$. Meanwhile, governments of developed countries also indirectly encourage their citizens to access this service in India, where it saves a lot of money compared to their own context, and "outsourcing children" is a viable option to make their citizens happy at the cost of third world women. This neo-colonialist approach from the developed countries and the economic growth centered policies of Indian government are deliberately pushing commercial surrogates to undertake commercial surrogacy.

\section{Reproductive choices and Coercion:} Contemporary bio ethical debates are predominantly focused on the choice aspects of participants in commercial surrogacy. Commissioning parents always have a high level of freedom and reproductive autonomy, who are predominantly from western countries, and are from wealthy context a large extent ${ }^{18}$. Whereas the commercial surrogates in India lack choices and it is believed that they do not have autonomous consent but express, as Amartya Sen coined "adaptive preference". Wilkinson is very critical of consent in a coercive context and he claims that coercion invalidates the consent ${ }^{19}$. Moreover, there is no assistance to protect the decision making authority of surrogates in (developing) countries. According to Donchin this is one of the main reasons why poor women lack autonomy ${ }^{20}$.

Bailey argues that coercion not just confined to the selection of surrogates but exists throughout the contract. In addition, she rejects the common idea that commercial surrogates are free and involved in autonomous choices. She says it is hype from Western media and there is no evidence for the claim ${ }^{10}$. Whereas Sama claims, "[t]he fertility market issues a price tag to reproductive tissues and then appropriates them in order to sell the unfulfilled dream to millions of people, under the rubric of choice and rights"21. In addition, Bryn Williams-Jones argues that "there is a clear contrast between surrogacy in developed and underdeveloped countries. In developed countries, surrogacy may be a choice for women to improve their financial situation and perform an altruistic act; in underdeveloped countries, surrogacy may be a form of slavery, reminiscent of the black nannies who raised white children in the American South during the slavery era, or in Apartheid South Africa"22. Petersen argues that women should reject Assisted Reproductive Services (ART) because they are coerced by a patriarchal society and their choices are not autonomous ${ }^{23}$. Though his argument comes from the perspective of ART for childless women it correlates with the commercial surrogate women in general. However, he argues from a developed country context where women have more choices and economic independence which can help them, to some extent, escape from coercion. Jaiswal contends the western liberal feminist perspective on surrogacy, which claims that surrogacy is an expression of reproductive choice and economic autonomy. She argues that in India socioeconomic conditions determine their choices (poverty, low education levels, marginalization in labor markets, and patriarchal family and social structures) ${ }^{15}$.

Ethical acceptability of Coercion in Commercial surrogacy: In this context, I argue that the primary objection to coercion is that it eliminates the freedom of a women and infringes upon the autonomy of the surrogate. It is very clear that coercion subordinates the woman's ability to reproduce freely and infringes upon her autonomy. It uses the woman's body for material benefit against her wishes which is morally 
unacceptable. However, humans always tend to gain from using their physical capacities; for example, education, physical labor, and knowledge development, in a way, helps to make money. So why do we oppose the involvement of poor women in commercial surrogacy? Here, the pressing issue is coercion which invalidates the reproductive right of poor women and victimizes their reproductive capacity. For example, in India the girls who trapped in sex trafficking are often coerced by brokers by showing economic benefits and false promises, many of the girls don't have any idea what they are going to do however they believe in the promise of the brokers who express that "you can get out of poverty if you come with me", they just follow their words and trapped in various fields like sex work, bonded labor and so on. Commercial surrogate recruitment also priorities economic benefit than the nature of job and its pros and cons. In addition you may ask how their autonomy is violated. It is very simple, in Indian context already women don't have any right over their body with regard to reproduction a large extent, it is their husband who decides. If this is the case, being commercial surrogate also should be the wish of her husband than herself. Then you may argue reproductive capacities of women are always subject to their husbands wish then whats different with normal pregnancy and commercial surrogacy in both contexts a woman is coerced by her husband. However, within family relationship it is a matter of shared responsibility where they involve in physical relationship and share genetic materials where in commercial surrogacy its mere a commercialization of body which is just used as means to an end. They are subjected by their husbands to be a reproductive slave. In addition to husband, they are subjects of the doctors and the commissioning parents. Saravanan interestingly denotes the word "inertness" as one of the prerequisites for being a commercial surrogate. Inertness is all about being like an object which is a subject of others than its own. If "inertness" is the prerequisite of a commercial surrogate then the commercial surrogacy industry considers the surrogate as an reproductive object, which does not have any wish and can be influenced and coerced. The commercial surrogacy industry forces the surrogate against her wishes and uses her to fulfill the desire of the commissioning parents on the one hand and their husbands and close family on the other hand.

Obviously, the whole argument of coercion in the context of economic benefit is of serious consideration. Why can't a woman benefit by using her reproductive capacity though she is coerced? For example, even advertisements influence customers to purchase a product and employ the marketing technique of repeatedly contacting the customer and persuading them to purchase the service. Is this coercion? Here, the customer has the choice to purchase or reject the product since they possess money, but in the commercial surrogacy context, commercial surrogates have reproductive capacity, which is really valuable, but do not have money. The clinics/brokers who are in need of surrogates swindle the reproductive services of poor women at the cost of their economic vulnerability. It is very important to note that the commercial surrogacy industry does not operate to develop the economic benefit of the rural poor, but it is a commercial industry which is completely profit centered and uses poor women as their profit-making machine. If these industries operate ethically, people automatically enroll and there is no need for force. On the other hand, in terms of business, coercion is never justified as a good business practice. Because it is very evident that predominantly most of the impoverished surrogates are persuaded by showing the economic benefits. To prevent coercion, few governments restrict payments for reproductive services; for example, in the UK commercial surrogates are not supposed to be paid, but they can receive compensation.

Besides, how these women involve in this, is it a well-informed business model in which the commercial surrogate is one of the stakeholders or just an object which is making profit for someone else. The commercial surrogate is 
exploited and subjected by the family, society, and even the government. Remarkably, she benefits the least compared with the others involved in this industry: for example, the clinics and commissioning parents. When we weigh the benefit and the risk of commercial surrogates, the risk is higher than the benefit. They are: economic, physical, and psychological risks; meanwhile, the whole idea of benefit is also questionable in the context of coercion. Coercion nullifies the idea of benefit. Benefit is about receiving an outcome without any compulsion and bargaining in exchange for ones labor. According to ILO forced labor defined as, "work or service extracted from a person under threat or penalty, which includes penal sanctions and the loss of rights and privileges, where the person has not offered him/herself voluntarily"24. In this context, no coercive activity is ethically justified as beneficial since it is executed by force and considered as forced labor.

More interestingly, coercion is culturally defined to an extent in India. For example, people still exercise forced marriages in India. However, it is not morally acceptable, so according to government forced marriage is a crime. If the government considers forced marriage as crime then it should treat forced reproduction the same. Moral standards should never be compromised for economic benefit especially by the rulers of a country. In addition, the husband's consent is never considered in medicine except in family planning in India; however, here, the husband's consent is used as a tool to moralize and force women into commercial surrogacy. Can a man force his wife to have a baby? That is also considered a crime since reproduction is about sharing responsibilities through mutual cooperation. Forcing a woman to sell reproductive services for the benefit of her family is never justified or legalized; however, current practices endorse the husband's consent and completely remove the ownership of the body of the women and subordinate her as a subject of her husband's consent, which is unethical.
On the other hand, the government also forces women to be a surrogate. The government policy on commercial surrogacy operates in two ways: it forces the women from India to undertake commercial surrogacy in order to benefit the economy, and the governments of developed countries promote access to reproductive services in India for cost-cutting reasons, ultimately for economic benefit. However, no one can justify forcing rural women into commercial surrogacy in a country where the maternal mortality rate is very high and $70 \%$ of women are affected by anemia during pregnancy ${ }^{25}$. Moreover, encouraging women to become commercial surrogates without firm regulations and laws increase the risk of coercion. Many arguments have been made for the development of commercial surrogacy in India, they are; "lower costs, the large number of women willing to engage in surrogacy, top-notch private healthcare, English-speaking providers, a business climate that encourages the outsourcing of Indian labor, world-famous tourist destinations, and the total absence of government regulation" (Points 2008). Meanwhile, Points is not clear on how women "willingly" participate in commercial surrogacy; however, he affirms the complete absence of government regulation. In terms of social justice, the government is the guardian of its people and it should never use its citizens to make a profit. It is the government's moral responsibility to protect these vulnerable communities rather than forcing them to undertake commercial surrogacy through the private sector in the name of economic development. Consequently, the government has failed in its duty of protecting its vulnerable citizens from coercion.

Obviously, most of the commercial surrogates engage in commercial surrogacy secretly which cuts off their social interactions and alienates them from their loved ones. They lack social acceptance for being a commercial surrogate; on the other hand, they experience tremendous force by families which creates "reproductive refugees". I deliberately call them "reproductive refugees" because of their status in society. It is 
the government's duty to help them come out of the crisis and put a stop the coercion. Protecting vulnerable groups from coercion and exploitation is always an important thing to be prioritized. Universal Declaration of Bioethics and Human Rights calls for protecting vulnerable communities in order to sustain their human dignity, promote their human rights and fundamental freedom. Article 8 affirms, "In applying and advancing scientific knowledge, medical practice and associated technologies, human vulnerability should be taken into account. Individuals and groups of special vulnerability should be protected and the personal integrity of such individuals respected"26. In this context, capitalizing on human vulnerability to increase profits by using reproductive technologies is against human rights, and consequently plunders the human dignity of a person. So it is the government's responsibility to enhance the choices of commercial surrogates and protect them from the coercive forces of private sector clinics and patriarchal society in addition to rectify the compromising policies.

A call for change: Response to coercion in commercial surrogacy varies from exploitation to ethics of care. Humbyrd calls for a Fair Trade International Surrogacy ${ }^{27}$ where surrogates are fairly treated. However, comparing reproductive services to coffee trade and coming to a conclusion that fair trade international surrogacy is a solution may be misleading since human beings and human values are involved in the commercial surrogacy industry.

Shalev remarks that the market is driven by forprofit motivation where there is no moral ideal of personal freedom and she emphasizes that the liberal autonomy based approach alone never solves the problem and it should be supplemented by an ethics of care based on responsibility, cooperation, and dependence. She explains, "An ethic of care and responsible self-restraint requires a shift in consciousness: from calculation of self-interest and benefit to contemplation of our mutual vulnerability and interdependence; from observation of others as external objects and instruments for our own ends, to inner awareness of the seamless web of life and relationship in which we are implicated by our very nature as human beings" 28 . Unnithan also affirms the crisis and calls for contextually-based ethics which moves beyond the biomedical frame and issues of choice, consent and access alone. She is citing Kleinmans distinction between ethics and morality and calls for the development of morality which is based on social commitments may be the answer to solve the issue. On the other hand her idea sounds like John Harris' "Green Paper" and "White Paper" concept: however, she emphasizes practical commitment and action over academic discussion ${ }^{16}$.

On the whole, coercion is never justified, though it benefits the economic development of poor communities, since it erases the reproductive freedom of every poor commercial surrogate and prioritizes money over a woman's reproductive capacities and creates "reproductive refugees". With regard to economic benefit, it hardly benefits the women who are involved in commercial surrogacy; however, it puts them under tremendous physical and psychological risk. Though the government supports the commercial surrogacy industry it is very important to note that people are the priority and it is the duty of everyone to protect the vulnerable communities from coercive forces of economic development.

Conclusion: The issue of coercion of rural, poor, women in the commercial surrogacy industry in India reveals how vulnerable poor women are! Obviously, we can understand the lack of the government and private sector's commitment on the issue. Whatever the case, coercion should be curtailed since it is unethical and commercial surrogacy in India should be regulated in order to ensure a better future for women since it is impossible to ban commercial surrogacy and the successive ban may lead poor women to become more vulnerable position of exploitation. In this context, it is very 
important to protect the commercial surrogates from coercion in order to ensure their human dignity, reproductive rights, and fundamental freedom. Personally $I$ think the following suggestions can help to eradicate coercion since it is unethical. The following suggestions will be helpful to empower the autonomy of rural women which will help to eliminate coercion and ensure justice for the commercial surrogates in India.

1. Commercial surrogate's consent should be mandatory and the consent should be an "informed consent" rather than "coercive consent."

2. Availability of alternative choices should be encouraged. Empowering woman's decision making capacity by protecting their reproductive rights can eliminate coercion.

3. Promoting the husband's consent which is the root of coercion, should be made illegal and seeking husband's consent should be stopped.

4. Broker's involvement in recruiting commercial surrogates should be stopped and we should find a better way to recruit surrogates through a transparent manner without coercion.

5. Fixed compensation procedure should be introduced to protect commercial surrogates from cheap bargaining and coercion.

6. Awareness and education to the rural women with regard to their choices and rights in commercial surrogacy and to the intending parents about the best, ethical practices in commercial surrogacy. This will empower commercial surrogates and eliminate coercion.

Acknowledgment: I thankfully remember the guidance of Prof.Kris Dierickx and comments by Prof.Pascal Bory on this manuscript.

Author's contribution: Author conceived the idea, perceived the knowledge, and drafted the manuscript.

\section{Conflict of interest: None}

\section{References:}

1. Lakshmanan AR. Report No. 228 AUGUST 2009. October. New Delhi; 2009.

2. Mahabal KB. Tehelka - India's Independent Weekly News Magazine. 2011; Available from:

http://www.tehelka.com/story_main49.asp?file name $=$ Ws080611ChildLabour.asp\#

3. Wertheimer A. Exploitation and commercial surrogacy. Denver Univ Law Rev. 1997;74(4):1215-30.

4. Gamble N. Crossing the line: the legal and ethical problems of foreign surrogacy. Reprod Biomed Online. 2009;19(2):151-2.

5. Yasin F. Booming Surrogacy Industry in India Raises Legal, Social Concerns [Internet]. March 10. 2011. Available from: http://www.globalpressinstitute.org/globalnews/asia/india/booming-surrogacy-industryindia-raises-legal-social-concerns?page $=2$

6. Pande A. It May Be Her Eggs But It's My Blood": Surrogates and Everyday Forms of Kinship in India. Qual Sociol [Internet]. 2009;32(4):379-97. Available from: http://www.springerlink.com/index/10.1007/s 1 1133-009-9138-0

7. Pande A. Commercial Surrogacy in India: Manufacturing a Perfect Mother-Worker. Signs J Women Cult Soc [Internet]. 2010;35(4):969-92. Available from: http://www.journals.uchicago.edu/doi/abs/10.1 086/651043

8. Pande A. Not an "Angel", not a "Whore": Surrogates as "Dirty" Workers in India. Indian J Gend Stud [Internet]. 2009;16(2):141-73. Available from: http://ijg.sagepub.com/cgi/doi/10.1177/097152 150901600201

9. Pande A. " At Least I Am Not Sleeping with Anyone ": Resisting the Stigma of Commercial Surrogacy in India. Fem Stud 36. 2010;2(2):292-312.

10. Bailey A. Reconceiving Surrogacy: Toward a Reproductive Justice Account of Indian Surrogacy. Hypatia [Internet]. $2011 \mathrm{Nov}$ 9;26(4):715-41. Available from: http://doi.wiley.com/10.1111/j.15272001.2011.01168.x

11. Sandel MJ. Michael J. Sandel. Rev Lit Arts Am. 2001;21:77-97.

12. Pande A. Commercial Surrogacy in India: Manufacturing a Perfect Mother-Worker. Signs J Women Cult Soc. 2010;35(4):969-91.

13. Whittaker a. Challenges of medical travel to global regulation: A case study of reproductive travel in Asia. Glob Soc Policy [Internet]. 2010 Dec 13 [cited 2012 May 8];10(3):396-415.

Available from: http://gsp.sagepub.com/cgi/doi/10.1177/14680 18110379981

14. Reddy S, Qadeer I. Medical Tourism in India: 
Progress or Predicament? Econ Polit Wkly. 2012;xlv(20):69-75.

15. Jaiswal S. Commercial Surrogacy in India: An Ethical Assessment of Existing Legal Scenario from the Perspective of Women's Autonomy and Reproductive Rights. Gend Technol Dev [Internet]. 2012 Mar 9 [cited 2012 May 12];16(1):1-28. Available from: http://gtd.sagepub.com/cgi/doi/10.1177/09718 5241101600101

16. Unnithan M. Infertility and Assisted Reproductive Technologies ( ARTs ) in a Globalising India : Ethics, Medicalisation and Agency. Asian Bioeth Rev. 2010;2(1):3-18.

17. Qadeer I. Benefits and threats of international trade in health: A case of surrogacy in India. Glob Soc Policy [Internet]. 2010 Dec 13 [cited 2012 May 12];10(3):303-5. Available from: http://gsp.sagepub.com/cgi/doi/10.1177/14680 181100100030206

18. Crozier GKD, Martin D. How to address the ethics of reproductive travel to developing countries: a comparison of national selfsufficiency and regulated market approaches. Dev World Bioeth [Internet]. 2012 Apr [cited 2012 May 12];12(1):45-54. Available from: http://www.ncbi.nlm.nih.gov/pubmed/2242045 1

19. Wilkinson S. The exploitation argument against commercial surrogacy. Bioethics [Internet]. 2003 Apr;17(2):169-87. Available from:

http://www.ncbi.nlm.nih.gov/pubmed/1281218 3

20. Donchin A. Reproductive tourism and the quest for global gender justice. Bioethics [Internet]. 2010 Sep [cited 2012 May 12];24(7):323-32. Available from: http://www.ncbi.nlm.nih.gov/pubmed/2069091 6

21. ARTs and Women [Internet]. New Delhi: Sama; 2006. Available from: http://www.samawomenshealth.org/pubs/book .pdf

22. Bryn Williams-Jones. Commercial Surrogacy and the Redefinition of Motherhood. J Philos Sci Law [Internet]. 2002;2. Available from: http://www6.miami.edu/ethics/jpsl/archives/pa pers/comsur_williamsjones.html

23. Petersen TS. A woman's choice? - on women, assisted reproduction and social coercion. Ethical Theory Moral Pract. 2003;7:81-90.

24. Ruwanpura KN, Rai P. Forced Labour: Definitions , Indicators [Internet]. Geneva; 2004. (18). Available from:

http://www.ilo.org/wcmsp5/groups/public/--ed_norm/---

declaration/documents/publication/wcms_081 991.pdf

25. Mittal S. Addressing Iron Deficiency Anemia:
12 x 12 Initiative [Internet]. New Delhi; 2012. Available from: http://whoindia.org/en/Section6/Section324_1 467.htm

26. Report of IBC on the Principle of Respect for Human Vulnerability and Personal Integrity. Paris; 2011.

27. Humbyrd C. Fair trade international surrogacy. Dev World Bioeth [Internet]. 2009 Dec [cited 2012 Mar 5];9(3):111-8. Available from: http://www.ncbi.nlm.nih.gov/pubmed/1950829 0

28. Shalev C. An Ethic of Care and Responsibility: Reflections on Third-Party Reproduction. Med Stud [Internet]. 2012 Mar 23 [cited 2012 May 6]; Available from: http://www.springerlink.com/index/10.1007/s1 2376-012-0074-z 